\title{
Limites do uso da força policial no Estado de São Paulo
}

\author{
SAMIRA BUENO ${ }^{1}$ \\ RENATO SÉRGIO DE LIMA ${ }^{2}$ \\ Marco Antônio Carvalho Teixeira ${ }^{2}$ \\ 1 Fórum BRAsileiro de Segurança Pública (FBSP), SÃo PaUlo - SP, BRASIL \\ 2 Fundação Getulio Vargas (FGV EAESP) / Escola de Administração Pública de SÃo PaUlo, SÃo PaUlo - SP, Brasil
}

\begin{abstract}
Resumo
A polícia constitui o principal mecanismo encontrado pelo Estado moderno para garantir a manutenção da lei e da ordem, tendo como prerrogativa a regulação das relações sociais mediante força física como ato legítimo e constitutivo de sua função. Desse modo, ao mesmo tempo que representa a autoridade para intervir quando necessário for, pode constituir um poderoso instrumento de violação de direitos dos cidadãos quando faz uso abusivo da força, em especial a letal. Este artigo apresenta uma análise descritiva das ocorrências de letalidade policial no Estado de São Paulo tendo por base a análise dos boletins de ocorrência dos casos de morte decorrente de intervenção policial. Os resultados indicam que, mesmo diante da redução expressiva dos homicídios dolosos, a letalidade da polícia cresceu substancialmente ao longo dos anos 2000, vitimando desproporcionalmente adolescentes e jovens, pretos e pardos. Concluímos que as polícias paulistas têm se excedido no uso da força letal e sugerimos o fortalecimento do controle interno das corporações para o enfrentamento do problema.
\end{abstract}

Palavras-chave: Segurança Pública. Polícia. Homicídio. Letalidade. Morte decorrente de intervenção policial.

\section{Police use of deadly force in the State of São Paulo}

\begin{abstract}
The police constitute the main mechanism found by the modern state to guarantee the maintenance of law and order, with the prerogative of regulation of social relations through physical force as a legitimate and constitutive act. While the police represent the authority to intervene when necessary, they may violate citizens' rights when making abusive use of force, especially lethal force. This article presents a descriptive analysis of reports on cases where police used lethal force in the State of São Paulo. The results indicate that, even in the face of a significant reduction in homicides, the use of deadly force by the police increased substantially during the 2000s, disproportionately affecting black people, particularly adolescents and young adults. The research concludes that the police have exceeded the use of deadly force and suggest strengthening the police's internal control to address the problem.
\end{abstract}

Keywords: Public Security. Police. Murder. Deadly Force. Death resulting from police intervention.

\section{Límites del uso de la fuerza policial en el estado de São Paulo}

\section{Resumen}

La Policía constituye el principal mecanismo encontrado por el estado moderno para garantizar el mantenimiento de la ley y del orden, teniendo como prerrogativa la regulación de las relaciones sociales a través de la fuerza física como acto legítimo y constitutivo de su función. Así, al mismo tiempo que representa la autoridad para intervenir cuando es necesario, puede constituir un poderoso instrumento de violación de derechos de los ciudadanos cuando hace uso abusivo de la fuerza, en especial, la letal. Este artículo presenta un análisis descriptivo de los casos de letalidad policial en el estado de São Paulo tomando como base el análisis de los reportes de los casos de muerte derivados de la intervención policial. Los resultados indican que, incluso ante la reducción significativo de los homicidios, la letalidad de la policía creció sustancialmente durante los años 2000, victimando desproporcionadamente a adolescentes y jóvenes, negros y pardos. Concluimos que las policías paulistas se han excedido en el uso de la fuerza letal y sugerimos el fortalecimiento del control interno de las corporaciones para enfrentar el problema.

Palabras clave: Seguridad pública. Policía; Homicidio. Letalidad. Muerte derivada de intervención policial. 


\section{INTRODUÇÃO}

A redução dos homicídios em São Paulo mobilizou bastante interesse da academia em busca de explicações para uma queda tão acentuada e contínua por mais de uma década e meia (FERREIRA, LIMA e BESSA, 2009; MANSO, 2012; NERY, 2016; PERES, VICENTIN, NERY et al., 2011; WILLIS, 2013). Até 1999, no entanto, o estado sofria com o aumento dos indicadores de criminalidade, em especial os homicídios dolosos, que chegaram ao seu recorde quando fizeram 12 mil vítimas em apenas um ano.

Os motivos apontados para essa redução drástica na violência letal são objeto de polêmicas e disputas no campo acadêmico e no debate público. Isso porque um grupo de estudiosos e etnógrafos defende que essa redução foi motivada em especial pela presença e ação do crime organizado - basicamente o Primeiro Comando da Capital (PCC) - regulando a vida nas periferias das cidades paulistas (DIAS, 2009; FELTRAN, 2010, 2012; MANSO, 2012; WILLIS, 2013). Segundo essa teoria, o PCC teria sido capaz de impor o monopólio privado do exercício da violência física nas prisões e, com o tempo, expandido sua capacidade de mediar conflitos também para as ruas. Se antes esses espaços eram dominados por gangues e disputas de diferentes grupos; à medida que a facção se tornou hegemônica, o crime passou a regular condutas e conflitos do cotidiano da sociedade segundo códigos próprios. Assim, uma dívida de droga que anos antes inevitavelmente resultaria em um conflito com várias mortes passou a ser intermediada pelo PCC mediante "debates" em tribunais formados por membros do comando, que decidem em sentença coletiva a punição mais adequada. Essa chave analítica destaca o papel que o crime organizado ocupou na mediação e administração de conflitos sociais, em detrimento do Estado, e como influencia as próprias dinâmicas de sociabilização desses territórios (DIAS, 2009). Bastante polêmica, essa teoria tem sido fortemente rechaçada pelos agentes estatais, mas ganha cada vez mais adesão na academia e na imprensa.

Outra vertente de pesquisadores tem defendido que, a despeito de o crime organizado ter tido algum impacto na redução dos homicídios, esta ocorreu em todo o Estado, impossibilitando a afirmação categórica de que teria sido ele o responsável, já que dificilmente possuiria essa capilaridade, especialmente no início dos anos 2000. Embora não neguem que o PCC possa ter tido influência na redução dos homicídios, destacam a combinação de uma série de medidas adotadas pelo poder público a partir dos anos 2000 como os fatores que potencialmente mais influenciaram essa redução (FERREIRA, LIMA e BESSA, 2009; JUSTUS, KAHN e CERQUEIRA, 2016; LIMA, 2014; NERY, 2016; PERES, VICENTIN, NERY et al., 2011).

Assim, políticas como a lei seca - com o fechamento de bares (BIDERMAN, DE MELLO e SCHNEIDER, 2006; KAHN e ZANETIC, 2005) -, o controle de armas e a aprovação do Estatuto do Desarmamento (PERES, VICENTIN, NERY et al., 2011), mudanças demográficas (MELLO e SCHNEIDER, 2007), aprimoramento das rotinas de trabalho das polícias com a adoção de ferramentas tecnológicas que permitiram mais agilidade à sua ação, compatibilização de áreas das polícias Civil e Militar, reestruturação do departamento de investigação de homicídios e priorização das investigações envolvendo homicidas contumazes (FBSP, 2015), dentre outras, são fatores geralmente mobilizados como variáveis que podem ter contribuído para essa redução.

É muito provável que a associação de todas as variáveis indicadas tenha favorecido a redução dos homicídios, mas, ainda que algumas tenham prevalência nesse processo, é difícil determinar a participação de cada uma. Essa redução, no entanto, não foi acompanhada dos números de mortes em decorrência de intervenções policiais que, pelo contrário, subiram no mesmo período. Enquanto os homicídios dolosos passaram de 12.475 mortes em 2001 para 4.377 em 2016, redução de 65\% no número de vítimas, as mortes em decorrência de intervenções das polícias civil e militar passaram de 605 vítimas em 2001 para 856 em 2016, incremento de $42 \%$. Isso significa dizer que a taxa de homicídios variou de 30 por 100 mil habitantes para 7,9 , e as mortes decorrentes de intervenções policiais saltaram de 0,8 para 1,9 por 100 mil habitantes. 


\section{Gráfico 1}

Taxas de homicídio doloso e morte decorrente de intervenção policial - Estado de São Paulo, 1996-2016

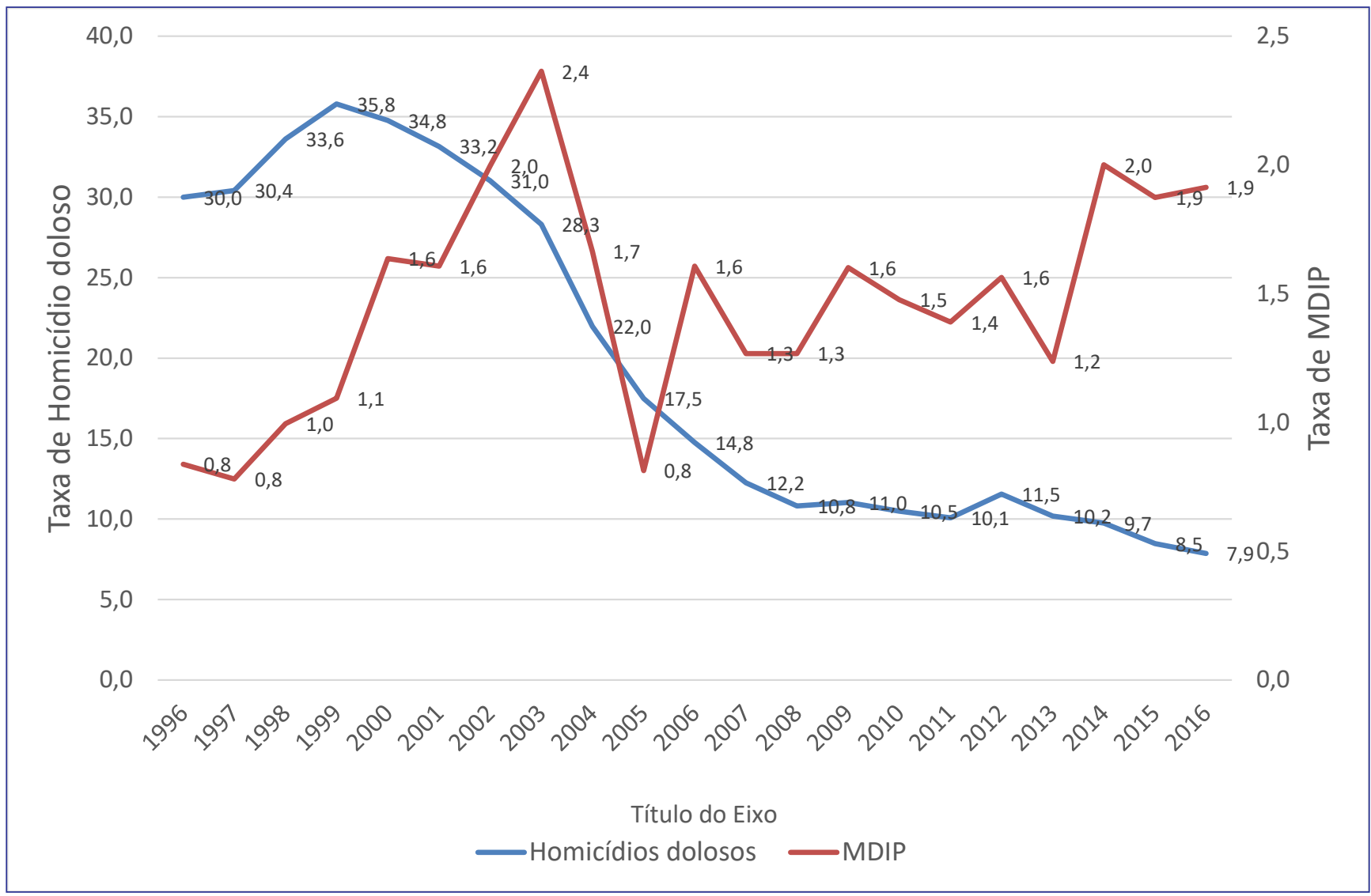

Fonte: Coordenadora de Análise e Planejamento da Secretaria de Estado da Segurança Pública.

Esses resultados assumem contornos mais intensos quando analisamos apenas os municípios que concentram os maiores números de ocorrência de letalidade decorrente de intervenção policial, visto que, neles, a redução dos homicídios dolosos foi ainda superior à média estadual. A Tabela 1 apresenta a seleção das cidades que concentraram a maior quantidade de casos de ocorrências de morte decorrente de intervenção policial (MDIP), categoria equivalente à resistência seguida de morte no período anterior a 2013. Dos vinte municípios com o maior número de casos em 2016, quinze coincidiam com as cidades que apresentaram o maior número de registros em 2001. 
Tabela 1

Seleção dos 15 municípios paulistas com os maiores registros de letalidade policial em 2001 e em 2016, em números absolutos

\begin{tabular}{|c|c|c|c|c|c|c|}
\hline \multirow[b]{2}{*}{ Municípios } & \multicolumn{3}{|c|}{ Letalidade policial } & \multicolumn{3}{|c|}{ Homicídio doloso } \\
\hline & 2001 & 2016 & $\begin{array}{c}\text { Variação } \\
\text { (em \%) }\end{array}$ & 2001 & 2016 & $\begin{array}{c}\text { Variação } \\
\text { (em \%) }\end{array}$ \\
\hline Estado & 605 & 856 & 41,5 & 12.475 & 4.377 & $-64,9$ \\
\hline São Paulo & 343 & 390 & 13,7 & 5.174 & 844 & $-83,7$ \\
\hline Guarulhos & 30 & 34 & 13,3 & 514 & 128 & $-75,1$ \\
\hline Campinas & 28 & 30 & 7,1 & 542 & 115 & $-78,8$ \\
\hline Santo André & 21 & 19 & $-9,5$ & 213 & 38 & $-82,2$ \\
\hline Osasco & 18 & 23 & 27,8 & 330 & 49 & $-85,2$ \\
\hline São Bernardo do Campo & 16 & 21 & 31,3 & 264 & 56 & $-78,8$ \\
\hline Guarujá & 9 & 15 & 66,7 & 157 & 25 & $-84,1$ \\
\hline Carapicuíba & 9 & 6 & $-33,3$ & 195 & 36 & $-81,5$ \\
\hline Santos & 7 & 8 & 14,3 & 103 & 19 & $-81,6$ \\
\hline Mauá & 7 & 5 & $-28,6$ & 184 & 28 & $-84,8$ \\
\hline Diadema & 5 & 13 & 160,0 & 237 & 33 & $-86,1$ \\
\hline São José dos Campos & 5 & 11 & 120,0 & 231 & 74 & $-68,0$ \\
\hline São Vicente & 5 & 9 & 80,0 & 166 & 20 & $-88,0$ \\
\hline Praia Grande & 4 & 12 & 200,0 & 137 & 23 & $-83,2$ \\
\hline Itaquaquecetuba & 4 & 13 & 225,0 & 209 & 45 & $-78,5$ \\
\hline Demais municípios & 68 & 247 & 263,2 & 3.819 & 2.844 & $-25,5$ \\
\hline
\end{tabular}

Fonte: Elaborada pelos autores com base nos dados da Coordenadoria de Análise e Planejamento da Secretaria de Segurança Pública do Estado de São Paulo; Resolução SSP-516/00; Diário Oficial do Estado de São Paulo.

Cidades como São Paulo, Guarulhos e Campinas apresentaram, respectivamente, redução de $-83,7 \%,-75,1 \%$ e $-78,8 \%$ de homicídios dolosos no período, ao passo que a letalidade decorrente da ação da polícia teve crescimento superior a $13 \%$ em São Paulo e Guarulhos e de 7\% em Campinas. Dos quinze municípios selecionados, apenas três tiveram redução no número de pessoas mortas em intervenções policiais, mas todos tiveram redução de ao menos $68 \%$ nos homicídios dolosos.

Dado que o emprego da força letal pelas polícias só deve ser feito de forma excepcional, quando houver ameaça à integridade física do policial ou de terceiros, e que deve obedecer aos princípios da legalidade, necessidade, proporcionalidade, moderação e conveniência (BRASIL, 2010), neste texto discutimos o paradoxo entre a redução da violência homicida no Estado de São Paulo e o aumento da letalidade consequente à intervenção policial por meio de uma análise descritiva das estatísticas.

O artigo está dividido em cinco seções, incluindo esta introdução. Na próxima seção descrevemos a metodologia utilizada; na terceira parte apresentamos o referencial teórico e alguns dos critérios normalmente utilizados para aferir uso da força pelas polícias; na quarta seção detalhamos informações sobre o perfil das vítimas policiais com base na comparação com as vítimas de homicídio doloso no Estado. Na seção 5 temos a conclusão e possibilidades de controle do uso da força dos agentes estatais.

\section{METODOLOGIA}

Em termos metodológicos, analisamos no universo dos boletins de ocorrência as nomenclaturas "morte decorrente de intervenção policial" e "homicídio doloso" registrados pela Polícia Civil entre os anos de 2013 e 2016 a fim de compreender o perfil das vítimas de ambas as ocorrências. 
A nomenclatura "morte decorrente de intervenção policial" é um desdobramento da categoria "resistência seguida de morte" ou "auto de resistência". O termo "auto de resistência"1 é referenciado no artigo 292 do Código Processual Penal (CPP), que autoriza o uso da força e de meios necessários para defender a si mesmo, a terceiros e/ou para vencer a resistência a prisão. Já a tipificação penal adotada no registro da ocorrência é o artigo 121 do Código Penal, o homicídio, que combinado ao artigo 23 prevê a "exclusão de ilicitude" quando o policial faz uso da força letal em estado de necessidade, legítima defesa e/ou em estrito cumprimento do dever legal (MISSE, GRILLO, TEIXEIRA et al., 2013).

O termo "auto de resistência" assumiu a nomenclatura de "resistência seguida de morte" no Estado de São Paulo entre as décadas de 1970 e 2010. No início de 2013, o termo foi substituído por "morte decorrente de intervenção policial", uma resposta do então recém-nomeado secretário da Segurança Pública Fernando Grella à Resolução n. 8, de 20 de dezembro de 2012, da Secretaria Especial dos Direitos Humanos (SDH) da Presidência da República, que recomendava a abolição das designações "resistência seguida de morte" e "autos de resistência" nos registros policiais (BUENO, 2014).

Para analisar os dados relacionados ao perfil das vítimas das ações policiais, foram solicitados à Secretaria de Segurança Pública, por meio da Lei de Acesso à Informação (n. 12.527/2011), todos os registros de "mortes decorrentes de intervenções policiais" do período compreendido entre 2013 e 2016. De posse da relação de todas as vítimas dessas ações em planilha Excel, foram geradas frequências dos casos por ano de acordo com o município e distrito policial da Polícia Civil/Companhia da Polícia Militar em que ocorreu a morte, além de informações sobre a vítima, como sexo, idade e raça/cor. Com base nas informações de latitude e longitude das ocorrências, foram gerados mapas com a distribuição geográfica das mortes por ano.

\section{Polícia e uso da força em sociedades democráticas}

Em todos os países do mundo a polícia tem sido a principal representação da força do Estado. Monjardet (2002) afirma que a polícia é a instituição responsável por possuir, mobilizar e regular o emprego da força nas relações sociais internas, ao passo que Bittner a define como um "[...] mecanismo de distribuição de força coercitiva não negociável, empregada de acordo com os preceitos de uma compreensão intuitiva das exigências da situação" (BITTNER, 2003, p. 138). Para Bayley (1994), a polícia moderna deve ser definida como um conjunto de pessoas que recebem autorização de um grupo de cidadãos para regular as relações interpessoais em um determinado território por meio do uso da força física. Dessa perspectiva, ela teria dois elementos essenciais ao cumprimento de sua função: a autoridade necessária para intervir quando for imperativo restaurar a ordem pública e o simbolismo da justiça que representa ao atuar na investigação e esclarecimento de crimes.

Seja como for, e independente da definição de polícia que se assume, o traço definidor das organizações policiais é, por excelência, a possibilidade de usar da força física como um mecanismo de administração dos conflitos sociais. E, embora a noção de Bittner (2003) aparente ser um tanto subjetiva, na prática é exatamente isso que está posto na discricionariedade policial. Ao fim e ao cabo, compete ao policial, burocrata do nível de rua (LIPSKY, 2010), decidir quais meios, instrumentos e intensidade de força vai dispender para controlar determinada situação.

Em realidade, o uso da força por parte dos policiais não se mostra apenas durante confrontos ou prisões, mas está posto por antecipação: é a possibilidade de usá-la que leva um cidadão a recorrer à polícia para solucionar um problema, instituição fundamental para qualquer democracia (MUNIZ, PROENÇA JUNIOR e DINIZ, 1999). De acordo com isso, a presença de um policial fardado na rua já é, por si só, demonstração de uso da força do Estado, ainda que simbólica, uma vez que a ameaça da força que esse agente carrega informa aos que estão ao redor os limites do que pode ou não ser feito. A polícia funciona como a garantia da ordem pública.

No entanto, a posição que a polícia ocupa na sociedade coloca-a também em uma constante zona de ambiguidade porque ao mesmo tempo que deve garantir direitos e proteção, é responsável pela repressão, sendo muitas vezes temida Diante disso, como é de esperar, o policial que atua no nível de rua precisa lidar permanentemente com essa tensão e ambiguidade no desenvolvimento do seu trabalho, não podendo ser confundida a discricionariedade que o sistema legal lhe confere com a arbitrariedade (BRETAS e PONCIONI, 1999).

Se a essência do mandato policial reside justamente na possibilidade de exercer o poder coercitivo pela força física de forma legítima e legal (MUNIZ, PROENÇA JUNIOR e DINIZ, 1999), torna-se importante destacar que o uso da força letal está previsto

\footnotetext{
${ }^{1}$ Sergio Verani (1996 apud MISSE, GRILLO, TEIXEIRA et al., 2013) afirma que o auto de resistência foi criado oficialmente em 1969 pela Superintendência da Polícia do Estado da Guanabara por meio da ordem de serviço no 803.
} 
como uma prerrogativa do mandato policial, desde que obedeça aos parâmetros da necessidade, legalidade, proporcionalidade, moderação e conveniência e seja utilizado para proteção da vida do policial e de terceiros.

Um dos maiores desafios encontrados em estudos sobre polícia é diferenciar o uso legítimo da força - que no nível mais extremo significa a morte de um terceiro - do abuso. Mesmo as normativas internacionais ${ }^{2}$ que regulam o uso da força pelas polícias, como o documento da ONU "Princípios Básicos sobre o Uso da Força e Armas de Fogo pelos Funcionários Responsáveis pela Aplicação da Lei", não diferenciam de forma precisa entre o uso da força e da violência. O princípio quarto do documento, por exemplo, estabelece que os responsáveis pela aplicação da lei devem utilizar meios não violentos antes de recorrer ao uso da força e de armas de fogo. Como a redação é vaga e não define critérios objetivos, dá margem para que sua interpretação desconsidere "[...] procedimentos de verbalização, de negociação, ou de técnicas defensivas desarmadas como formas legítimas (e não violentas) de utilização da força para a resolução de conflitos" (INSTITUTO SOU DA PAZ, 2013, p. 243).

De fato a legislação que regulamenta o uso da força pelos agentes estatais é bastante recente no Brasil. A primeira normativa sobre o tema foi publicada apenas em 2010 (BRASIL, 2010) e dispõe sobre o uso da força pelos agentes da segurança pública das polícias Federal, Rodoviária Federal, Ferroviária Federal e Força Nacional. Para estados e municípios, a portaria tem o poder apenas de recomendar, vinculando o repasse de recursos à observância das diretrizes definidas ${ }^{3}$ (BUENO, 2014). Entretanto, desde sua implantação não existe um sistema de monitoramento do Ministério da Justiça com relação ao tema para as unidades da Federação, o que inviabiliza o condicionamento de repasse de verbas à observância das diretrizes recomendadas.

Em 2014 foi aprovada a lei 13.060, que disciplina o uso de instrumentos de menor potencial ofensivo por agentes de segurança pública. A lei restringe o uso de arma de fogo nas situações de pessoa em fuga, desarmada ou sem representar risco imediato de morte ou de lesão aos agentes de segurança pública ou a terceiros; e contra veículo que desrespeite bloqueio policial em via pública, exceto quando o ato represente risco de morte ou lesão aos agentes de segurança pública ou a terceiros. De modo complementar, a lei ainda determina que os cursos de formação e capacitação de agentes de segurança pública incluam em seus conteúdos programáticos o uso de instrumentos não letais.

Apesar do arcabouço legal disponível para avaliar a necessidade, legalidade e proporcionalidade do uso da força, é difícil diferenciar o uso legítimo da força letal de casos de abuso.

Skolnick e Fyfe (1993) defendem que o ponto mais crítico para determinar se houve violência ou não por parte de um policial reside justamente no escalonamento progressivo do uso da força: o quanto de força e quais instrumentos um policial deve mobilizar em cada uma das situações em que se vê envolvido no seu cotidiano? Como diferenciar o uso legítimo da força de um episódio em que houve abuso ou qualquer tipo de ilegalidade?

Internacionalmente a literatura tem destacado três critérios para mensurar se a polícia está utilizando excessivamente a força letal, dentre os quais destacamos: 1) a proporção de civis mortos pelas polícias em relação ao total de homicídios dolosos; 2) a relação entre civis mortos e policiais mortos; 3 ) a razão entre civis feridos e civis mortos pela polícia, chamada índice de letalidade (BUENO, 2014; CHEVIGNY, 1995; COSTA, 2004; LOCHE, 2010).

O primeiro critério tem por objetivo contextualizar a letalidade da polícia no cenário da violência urbana de modo geral (COSTA, 2004). De acordo com ele, um território pode aparentemente ter muitos casos de uso da força letal pela polícia, mas seu número ser pouco representativo diante do total de homicídios. Ou, ao contrário, o número de mortes em decorrência de intervenções

\footnotetext{
${ }^{2}$ Os princípios internacionais que orientam o uso da força e da arma de fogo estão expressos nos seguintes documentos: 1) Código de Conduta para os Funcionários Responsáveis pela Aplicação da Lei, adotado pela Assembleia Geral das Nações Unidas na sua Resolução 34/169, de 17 de dezembro de 1979; 2) Princípios Básicos sobre o Uso da Força e Armas de Fogo pelos Funcionários Responsáveis pela Aplicação da Lei, adotados no XVIII Congresso das Nações Unidas para a Prevenção do Crime e o Tratamento dos Delinquentes, realizado em Havana, Cuba, de 27 de agosto a 7 de setembro de 1999; 3 ) Princípios Orientadores para a Aplicação Efetiva do Código de Conduta para os Funcionários Responsáveis pela Aplicação da Lei, adotados pelo Conselho Econômico e Social das Nações Unidas na sua resolução 1989/61, de 24 de maio de 1989; e 4) Convenção Contra a Tortura e outros Tratamentos ou Penas Cruéis, Desumanas ou Degradantes, adotada pela Assembleia Geral da ONU em sua XL Sessão, realizada em Nova York, em 10 de dezembro de 1984 , e promulgada pelo Decreto no 40, de 15 de fevereiro de 1991. Como os documentos foram aprovados durante Assembleia das Nações Unidas, a vinculação dos Estados membros é automática e passam a compor as normativas internacionais de proteção aos direitos humanos (PINC, 2011).

${ }^{3} \mathrm{O}$ documento é formado por 25 diretrizes, das quais destacam-se: “[...] o uso da força por agentes de segurança pública deverá obedecer aos princípios da legalidade, necessidade, proporcionalidade, moderação e conveniência; [...] os agentes de segurança pública não deverão disparar armas de fogo contra pessoas, exceto em casos de legítima defesa própria ou de terceiro contra perigo iminente de morte ou lesão grave; [...] não é legítimo o uso de armas de fogo contra pessoa em fuga que esteja desarmada ou que, mesmo na posse de algum tipo de arma, não represente risco imediato de morte ou de lesão grave aos agentes de segurança pública ou terceiros; [...] não é legítimo o uso de armas de fogo contra veículo que desrespeite bloqueio policial em via pública, a não ser que o ato represente um risco imediato de morte ou lesão grave aos agentes de segurança pública ou terceiros [...]" (BRASIL, 2010, p. 3).
} 
policiais pode aparentar ser baixo, mas corresponder a um elevado percentual do total de homicídios dolosos, indicando que há uso excessivo da força letal pela polícia local (BUENO, 2014). No Estado de São Paulo, a letalidade policial corresponde a 25\% de todos os homicídios, o maior coeficiente do país segundo dados do Anuário Brasileiro de Segurança Pública (FBSP, 2018).

No segundo critério afirma-se que deve existir certa proporcionalidade nas mortes de civis e policiais. Dessa lógica, quando o número de mortos pelas polícias é muito superior ao de policiais mortos, provavelmente a polícia está abusando do uso da força letal. Loche (2010) afirma que existe uma dificuldade normativa em estabelecer o que seria um grau aceitável de uso da força letal pela polícia. No entanto, o Federal Bureau of Investigation (FBI) trabalha com a proporção de 12 civis mortos para cada policial morto e Chevigny (1995), 10 para 1 (BUENO, 2014). Esse indicador parece problemático para mensurar o uso da força letal pelas polícias no Brasil porque supõe que todos os casos de mortos pela polícia e de policiais mortos teriam ocorrido em situações de confronto, e daí sucederia alguma proporcionalidade. Contudo estudos produzidos no Brasil indicam que cerca de $70 \%$ dos policiais brasileiros assassinados morrem fora do horário de serviço (FBSP, 2017), em geral no chamado "bico" (FERNANDES, 1973).

No terceiro critério afirma-se que, em condições de normalidade democrática, haveria um número maior de pessoas feridas do que mortas em ações policiais. Esse é um critério bastante difícil de ser avaliado no contexto nacional, seja pela falta de estatísticas, seja pelas características particulares destes episódios, que recorrentemente não são registrados pelas autoridades policias.

Outra possibilidade apontada aqui para mensurar o uso da força letal das polícias no Brasil diz respeito à proporção de civis mortos em relação ao número de prisões e apreensões em flagrante. Esse critério pode não ser adequado para outras realidades, mas como no Brasil e especificamente em São Paulo a maior parte das prisões ocorre em flagrante, muitas das quais após abordagens, aferir quantas mortes acontecem em relação ao número de prisões e apreensões de adolescentes em flagrante pode constituir um mecanismo relevante.

O Gráfico 2 apresenta a taxa de mortos pela PMESP a cada 1.000 prisões de adultos e a cada 1.000 apreensões de adolescentes no Estado de São Paulo entre 2013 e 2016. Os dados indicam que os adolescentes são mais vitimados que os adultos nas interações com os policiais, reforçando o componente etário como forte variável explicativa para a violência policial, que será objeto de discussão na próxima seção.

\section{Gráfico 2}

Taxa de mortos pela PMESP a cada 1.000 prisões e apreensões em flagrante, por faixa etária - Estado de São Paulo, 2013 a 2016

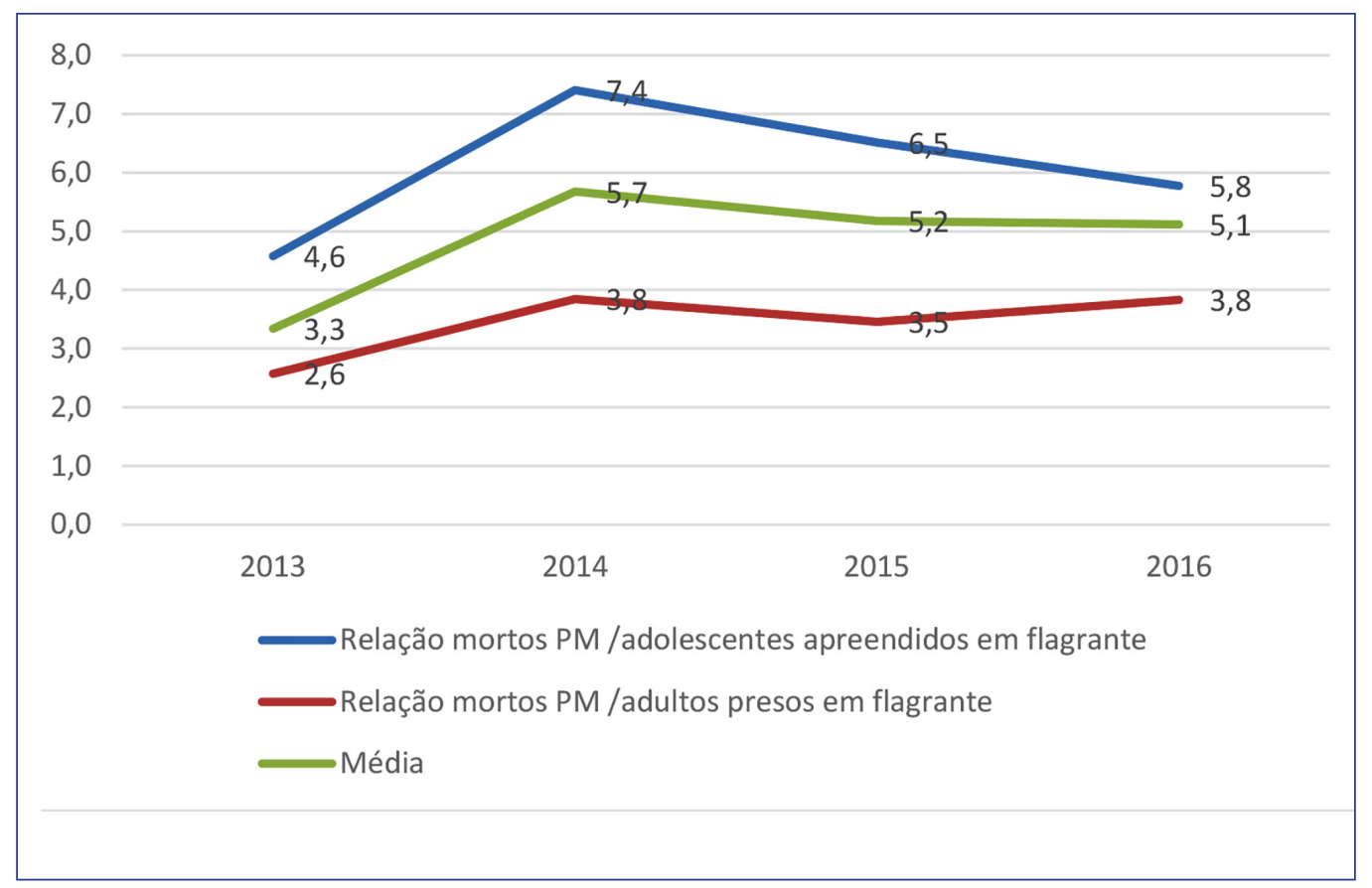

Fonte: Elaborado pelos autores com base nos dados da CAP/SSP. 


\section{RESULTADOS}

A Figura 1 apresenta a distribuição espacial das mortes em decorrência de intervenções policiais com base nos dados de latitude e longitude dos boletins de ocorrência de 2016. Os dados indicam que a maior parte das cidades paulistas não apresentou nenhuma ocorrência e que 20 municípios concentraram cerca de $70 \%$ de todos os casos de mortes decorrentes de intervenções policiais.

Figura 1

\section{Distribuição territorial das mortes decorrentes de intervenção policial,} números absolutos - São Paulo, 2016

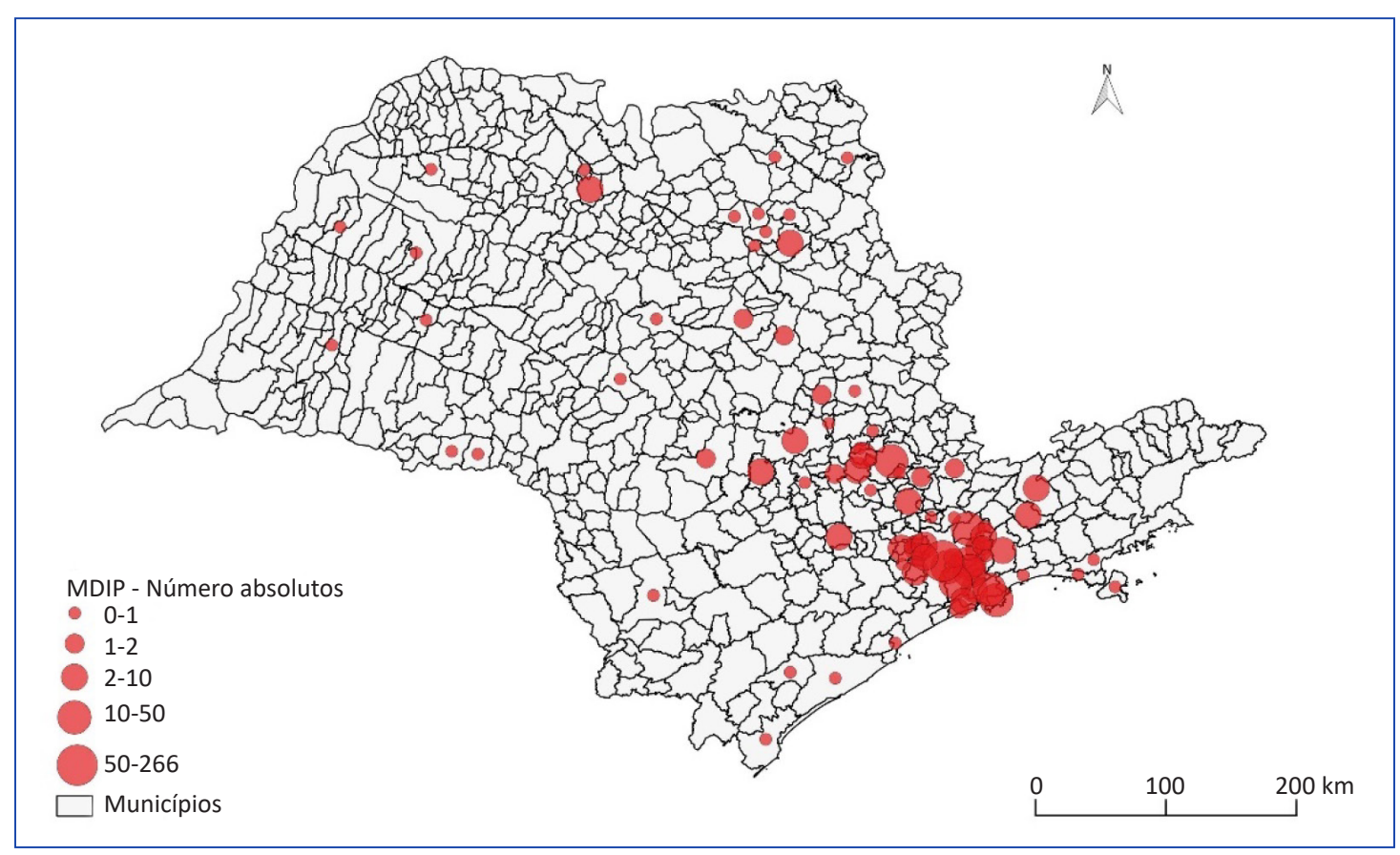

Fonte: Elaborada pelos autores com base nos dados da CAP/SSP-SP.

Verifica-se uma concentração da letalidade na capital, Região Metropolitana de São Paulo, Baixada Santista e em algumas regiões no interior do Estado, como em Ribeirão Preto e São José dos Campos. Uma hipótese explicativa é a presença do crime organizado de forma mais intensa nesses territórios, o que pode desencadear mais conflitos e consequentemente mais casos com resultado de morte envolvendo as ações policiais. Estas cidades também concentram maior contingente populacional e são as cidades mais ricas do Estado, mas não necessariamente aquelas que apresentam os maiores indicadores de violência.

A Figura 2 apresenta as taxas de MDIP na capital no período de 2013 a 2016. O primeiro ponto a ser destacado é o agravamento da letalidade na cidade de São Paulo ao longo do tempo. Outro dado extremamente preocupante na análise por distrito policial é que a taxa de MDIP em distritos policiais da periferia da Zona Leste ou da Zona Norte apresenta valores superiores a 10 por grupo de 100 mil habitantes, ou seja, maior que a taxa média de homicídios do Estado, que foi de 8,9 em 2016. Estudo produzido por Lester (1996) afirma que o ambiente no qual o indivíduo atua e a percepção de poder cometer ilegalidades sem qualquer consequência para sua carreira são fatores que influenciam a tomada de decisão do policial antes de fazer uso da força, em especial a letal. Trabalhar em áreas tidas como mais violentas e cujos indicadores socioeconômicos são piores pode influenciar na percepção do agente em relação ao risco a que está sujeito, estimulando-o a usar da força letal. 
Figura 2

Taxa de mortes decorrentes de intervenção policial - Taxa por distrito policial na cidade de São Paulo, 2013 a 2016

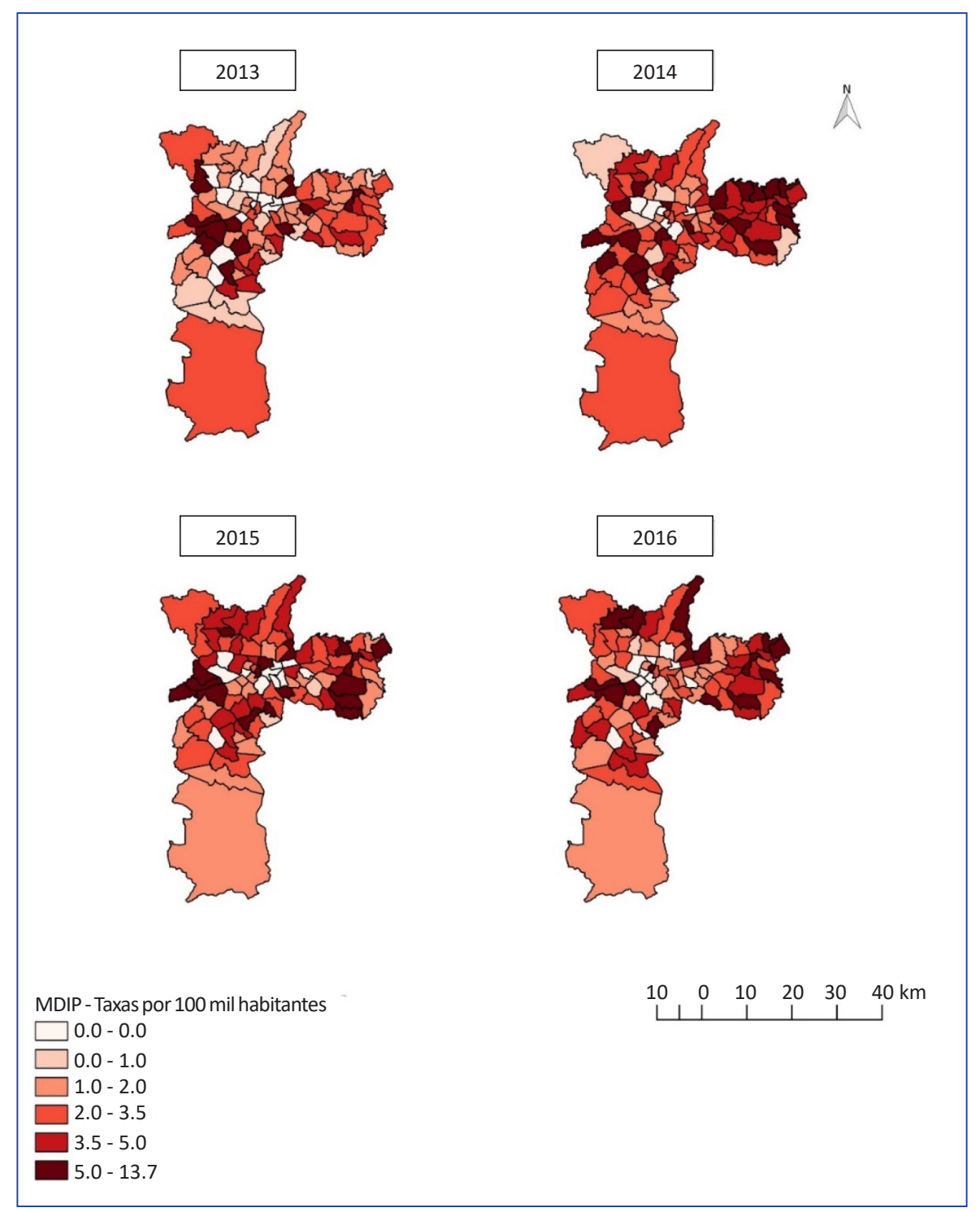

Fonte: Elaborada pelos com base nos dados da CAP/SSP. Estimativa populacional por DP produzida por Marcelo Batista Nery (2016) com dados da Fundação SEADE.

Já o discurso policial aponta que parte considerável do trabalho de policiamento ostensivo consiste na repressão ao crime com a tentativa de controle do mercado de drogas e o combate ao crime organizado, estratégias que seriam focalizadas em bairros periféricos com altas taxas de desorganização social. Nessa perspectiva seria natural que a letalidade policial se concentrasse nas regiões periféricas, enquanto os bolsões do centro não apresentam ocorrências. Também derivada dessa explicação, a visibilidade gerada nas ações reconhecidas como positivas e/ou legítimas no combate ao crime poderia influenciar a aceitação da população dos níveis de violência utilizados pela polícia, tornando mais palatáveis táticas que não seriam vistas da mesma forma em bairros de classe média. Isso, por si só, funcionaria como um mecanismo de restrição e controle ao uso da força policial em determinados territórios (BRUNSON e MILLER, 2006).

A análise da evolução dos casos quando considerada a Região Metropolitana de São Paulo também indica o agravamento da letalidade policial nos últimos anos (Figura 3). Municípios como Juquitiba, Guararema e Santa Isabel passam a apresentar altas taxas de letalidade policial, assim como a capital e as cidades tradicionalmente tidas como mais violentas, entre as quais Guarulhos, Carapicuíba e Osasco. 
Figura 3

\section{Taxa de mortes decorrentes de intervenção policial por município da} Região Metropolitana de São Paulo, 2013 a 2016

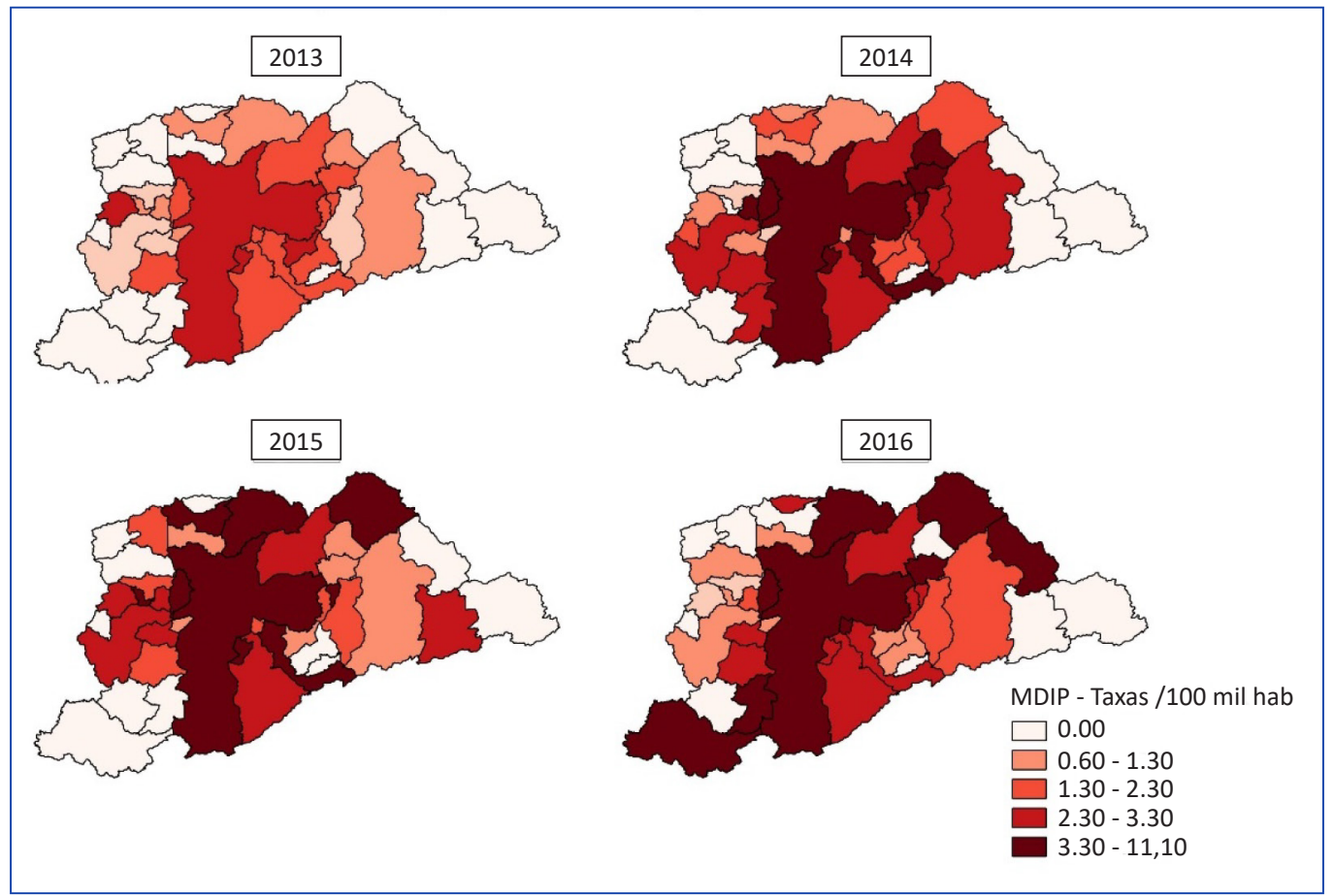

Fonte: Elaborada pelos autores com base nos dados da CAP/SSP. Estimativa populacional por DP produzida por Marcelo Batista Nery (2016) com dados da Fundação SEADE.

No mesmo sentido das explicações dadas pelos policiais, Kania e Mackey (1977) relacionam o número de mortes provocadas por ações da polícia em 50 estados norte-americanos ao risco de o policial ser vítima de um homicídio, ou seja, a violência da polícia seria uma resposta aos níveis de violência verificados no território, e isso implicaria zonas sem ações resultando em morte. Fyfe (1982) testa algumas das hipóteses de Kania e Mackey em 2.746 episódios em que policiais dos EUA usaram da arma de fogo, mas sem necessariamente ter resultado em morte. $O$ autor encontrou correlação entre a violência policial e os índices de criminalidade locais que poderiam representar ameaça aos policiais.

A prevalência de homens entre as vítimas da violência letal é um fenômeno que tem sido descrito em diversos trabalhos, mas nos casos de letalidade policial parece assumir proporções ainda maiores. Cano (1997), em um estudo, tendo por base os registros de "resistência seguida de morte" nos anos 1990, no Rio de Janeiro, concluiu que 94\% das vítimas eram do sexo masculino. Em São Paulo, os dados levantados indicam proporção ainda maior: mais de $99 \%$ das vítimas da polícia são homens (Tabela 2).

Tabela 2

Vítimas segundo sexo, homicídio e morte decorrente de intervenção policial - São Paulo, 2014 a 2016

\begin{tabular}{l|c|c|c|c|c|c}
\hline \multirow{2}{*}{$\begin{array}{c}\text { Vítimas } \\
\text { segundo sexo }\end{array}$} & \multicolumn{3}{c|}{ Homicídios } & \multicolumn{3}{c}{ MDIP } \\
\cline { 2 - 7 } & 2014 & 2015 & 2016 & 2014 & 2015 & 2016 \\
\hline Masculino & 85,3 & 87 & 85,2 & 99,7 & 99,3 & 99,6 \\
\hline Feminino & 12,3 & 13 & 12,9 & 0,0 & 0,4 & 0,2 \\
\hline Sem informação & 2,4 & 0,1 & 1,9 & 0,3 & 0,4 & 0,1 \\
\hline
\end{tabular}

Fonte: Elaborada pelos autores com base nos dados da CAP/SSP. 
Pesquisa desenvolvida por Brunson e Miller (2006) indica que, quando a polícia age de forma violenta em suas abordagens, consequentemente cresce a resistência dos cidadãos em obedecer às ordens policiais. Os autores também sugerem que negros apresentam maior grau de experiências negativas com as polícias, evidenciando que a relação entre raça e comportamento do indivíduo objeto da ação policial é influenciada pela forma como a corporação interage com a população de territórios mais vulneráveis do ponto de vista socioeconômico. No mesmo sentido, pesquisa divulgada pelo Datafolha revelou que pretos e pardos têm mais medo de serem vítimas de violência policial (MENA, 2017), enquanto brancos são mais aderentes à máxima "bandido bom é bandido morto". Já o Índice de Confiança na Justiça, da Fundação Getulio Vargas de São Paulo (FGV-SP), revela que brancos apresentam uma taxa de satisfação com a polícia superior à de negros (FÓRUM BRASILEIRO DE SEGURANÇA PÚBLICA, 2015). Kappeler, Sluder e Alpert (1994) afirmam que por serem mais vitimadas e terem proporcionalmente um número de encontros mais negativos com a polícia, as minorias tenderiam a ser mais críticas à atividade policial.

Os dados aqui compilados indicam que 62,1\% das vítimas das ações policiais em São Paulo entre 2013 e 2016 eram negros e $33,9 \%$, brancos, conforme gráfico abaixo.

\section{Gráfico 3}

Vítimas fatais de Intervenções Policiais no Estado de São Paulo, por raça/cor 2013-2016

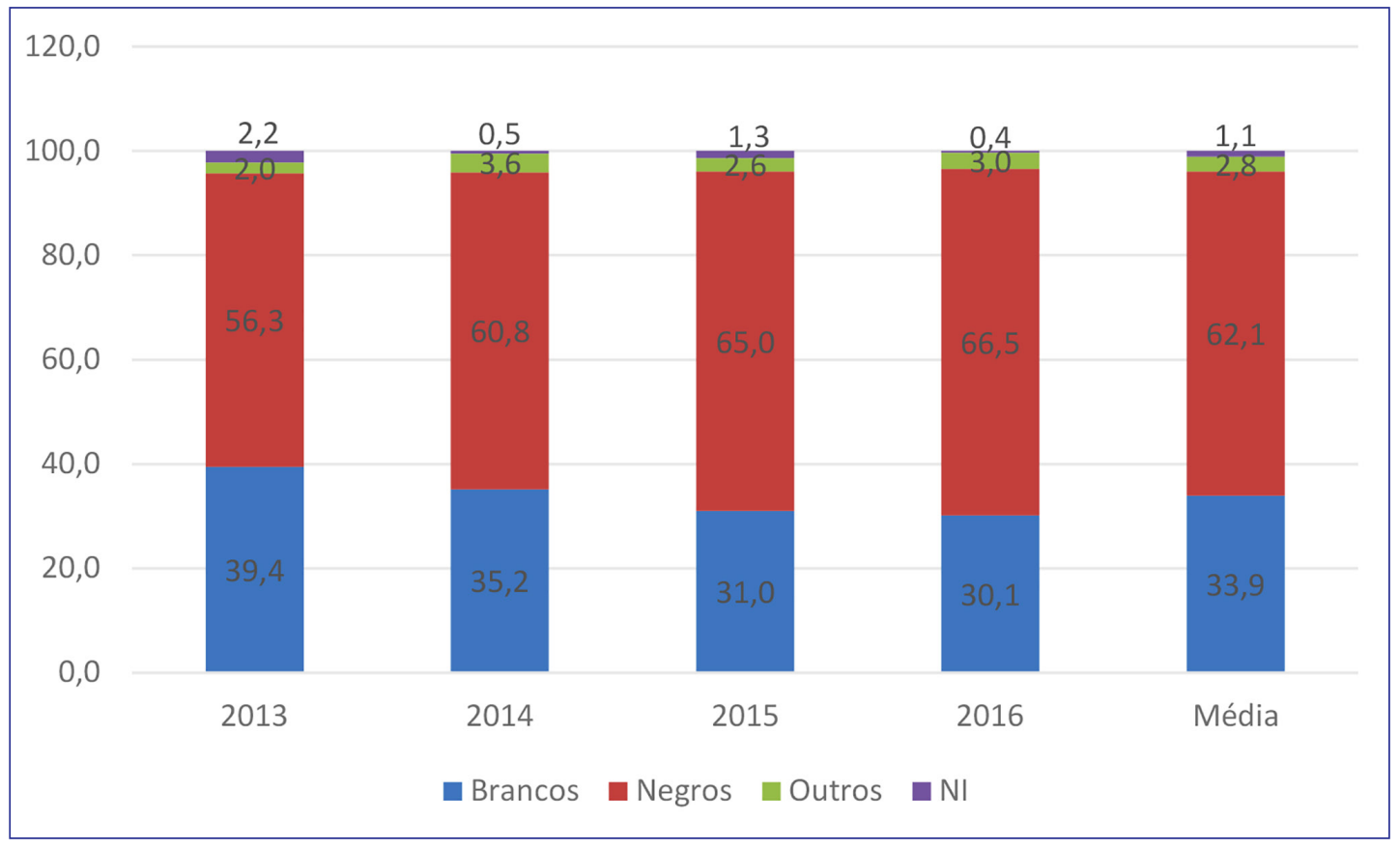

Fonte: Elaborado pelos autores a partir dos dados da CAP/SSP.

Verifica-se uma relação inversamente proporcional entre a população e as vítimas de homicídios praticados por policiais: enquanto os brancos representam $63,1 \%$ da população paulista, 30\% desta parcela é vítima da ação policial; já os negros, que representam $36,9 \%$ do total do Estado, são $66,5 \%$ das vítimas. 


\section{Gráfico 4}

Proporção de Negros e Brancos no total da população brasileira; entre as vítimas de homicídio e entre as vítimas de mortes decorrentes de intervenções policiais - Estado de São Paulo, 2016

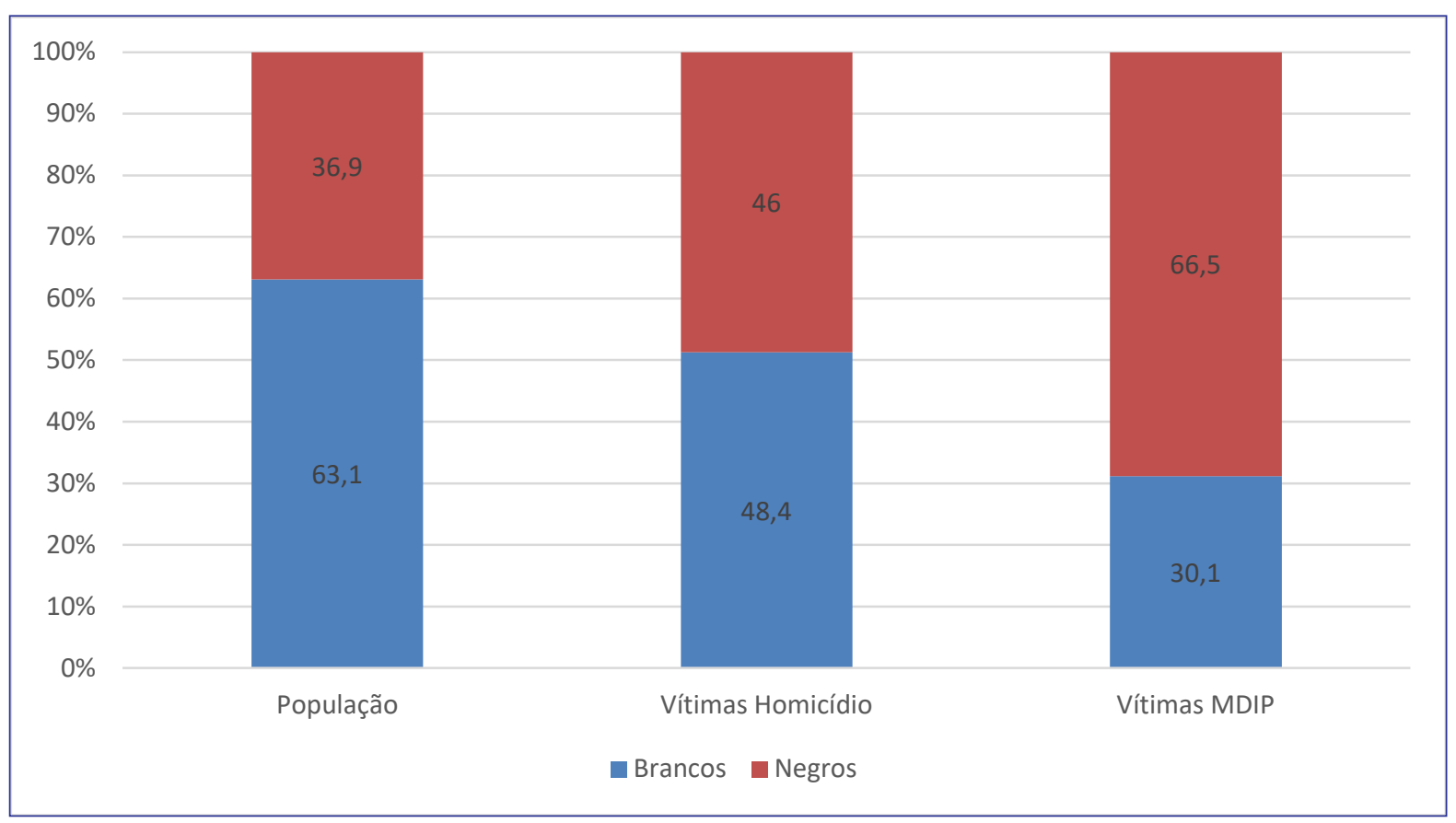

Fonte: Elaborado pelos autores a partir dos dados da CAP/SSP.

Brunson e Miller (2006), em pesquisas realizadas nos EUA, indicam que negros apresentam mais insatisfação e desconfiança em relação ao trabalho policial do que outros grupos étnico-raciais, o que estaria diretamente relacionado às suas experiências com a polícia. Estudos também indicam que a corporação atua de forma diferente em bairros de maior vulnerabilidade socioeconômico ou periferias em comparação com os bairros de classe média (KLINGER, 1997), o que também encontra respaldo na concentração dos casos de letalidade pela ação policial observada nas pesquisas brasileiras (CANO, 1997; SINHORETTO, BATITUCCI, MOTA et al., 2014) ${ }^{4}$.

Já na associação entre território e raça, Reinach, Rondinone e Moya-Latorre (2017) ${ }^{5}$ apresentaram recentemente, no Instituto de Tecnologia de Massachusetts (MIT), os dados de letalidade policial na cidade de São Paulo, em busca de explicações sobre o padrão de distribuição espacial das ocorrências e sua relação com os indicadores socioeconômicos. $O$ estudo demonstra que os distritos do centro expandido da capital paulista - que apresentam menor quantidade de casos de MDIP - concentram também $80 \%$ da população branca. Nas periferias da cidade, em distritos mais distantes do centro, onde a polícia produz mais mortes, residem $60 \%$ da população negra. Outro elemento trazido pelos autores apresenta a concentração da população jovem por região, indicando que ela se concentra majoritariamente nas regiões periféricas da cidade, enquanto a maioria dos moradores do centro expandido tem mais de 25 anos.

Reforçando esse cenário de desigualdade, Reinach, Rondinone e Moya-Latorre (2017) indicam que na área central a renda média do cidadão pode vir a ser vinte vezes superior à renda nas periferias, e que quanto mais distante do centro, mais aguda é essa diferença na renda média.

\footnotetext{
${ }^{4}$ Recentemente o Comandante da Rota fez uma afirmação do gênero, gerando grande polêmica. ADORNO, L. Abordagem nos Jardins tem de ser diferente da periferia, diz novo comandante da Rota. UOL, São Paulo, 24 ago. 2017. Disponível em: <https://noticias.uol.com.br/cotidiano/ultimas-noticias/2017/08/24/ abordagem-no-jardins-e-na-periferia-tem-de-ser-diferente-diz-novo-comandante-da-rota.html>. Acesso em:16 fev. 2018.

${ }^{5} \mathrm{O}$ estudo foi o resultado de um trabalho desenvolvido para a disciplina Geographic Information Systems no MIT, de autoria de Sofia Reinach, a quem agradecemos pelo envio dos dados. $\mathrm{O}$ artigo ainda não foi publicado.
} 
Os dados indicam que negros estão sobrerrepresentados entre as vítimas da polícia, o que pode ser verificado no Gráfico 5 , que apresenta as taxas de mortalidade por intervenções policiais por raça/cor. Verifica-se que a taxa de mortalidade entre negros é 3,5 vezes superior à taxa de mortalidade entre não negros.

\section{Gráfico 5}

Taxa de mortalidade por intervenções policiais, por raça/cor

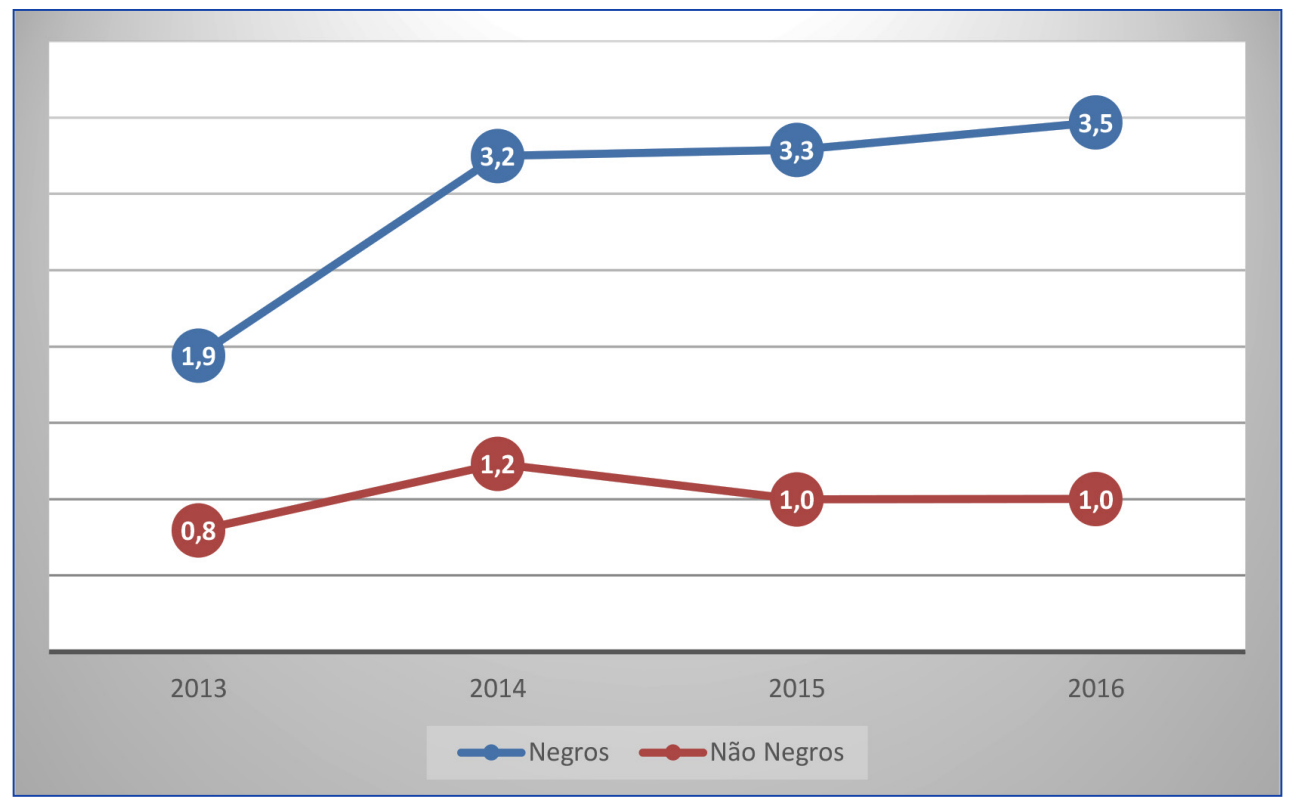

Fonte: Elaborado pelos autores a partir dos dados da CAP/SSP.

Em busca de respostas para essa pergunta, Cano (2014) testa a existência de viés racial no uso da força pelas polícias nos estados do Rio de Janeiro e São Paulo. O estudo demonstrou uma grande disparidade racial entre as vítimas de intervenções policiais comparativamente à população em geral, mas a precariedade dos dados disponíveis não permitiu avaliar se ela é necessariamente fruto de um viés na atuação dos policiais. No entanto, no caso fluminense, a cuja base de dados mais completa e consistente o estudo teve acesso, o autor confirmou a hipótese do viés racial no uso da força letal (CANO, 2014).

Também um trabalho produzido por Sinhoretto, Batitucci, Mota et al. (2014) aponta para a sobrerrepresentação de negros mortos pela ação das polícias em São Paulo, Rio de Janeiro, Distrito Federal e Minas Gerais. O estudo, desenvolvido a pedido do Ministério da Justiça, demonstrou a desproporção entre vítimas brancas e negras nas ações policiais resultando em morte, o que decorreria da filtragem racial nas ações policiais. Essa seletividade na ação da polícia é compreendida como um subproduto no campo da segurança pública da racialização nas relações sociais no Brasil, produzindo o racismo institucional.

Schlittler (2016) sugere que o protagonismo assumido pela Polícia Militar no controle do crime a partir dos anos 1970 e as demandas por mais segurança a qualquer custo têm produzido desigualdade racial. Amparada por um modelo de policiamento militarizado, cuja suspeita policial fundamenta-se na construção da categoria bandido, a PM estaria privilegiando a abordagem de jovens negros por identificar neles o elemento criminoso. Segundo a autora, os elementos que informam a suspeição são de natureza institucional e fruto da experiência prática, em que o tirocínio é utilizado para identificar o sujeito criminoso. Dessa perspectiva, o que está em jogo não são concepções individuais racistas dos policiais, e sim uma espécie de racismo institucional que faz parte da própria organização.

Já Hubert G. Locke (apud GELLER, 1996) afirma que, embora o número de negros feridos, mortos ou que registram queixas contra ações policiais seja desproporcionalmente representado no caso norte-americano, afirmar que existe um viés racial na atuação das polícias é impreciso, pois estes resultados variariam de acordo com perspectivas situacionais dos encontros, das estruturas organizacionais das polícias, e outras características individuais dos civis e policiais envolvidos. Fryer Junior (2016) direciona sua conclusão à mesma perspectiva ao afirmar que, ainda que negros e hispânicos tenham cerca de $50 \%$ mais 
chances de serem vítimas de violência por parte da polícia em abordagens que não resultem em morte, não seria possível estender a conclusão para os casos de violência letal.

Por fim, em relação à idade das vítimas, o Gráfico 6 mostra que os mortos em ações policiais são consideravelmente mais jovens que as vítimas de homicídio doloso no estado de São Paulo. O estudo de Cano (1997) no Rio de Janeiro, na década de 1990, mostrou que a maior parte das vítimas se concentrava na faixa de 20 a 24 anos. Em território paulista, 20 anos depois, os dados indicam que a maior parte das vítimas se concentra na faixa de 15 a 19 anos.

\section{Gráfico 6}

\section{Percentual das vítimas de Homicídio e MDIP por faixa etária}

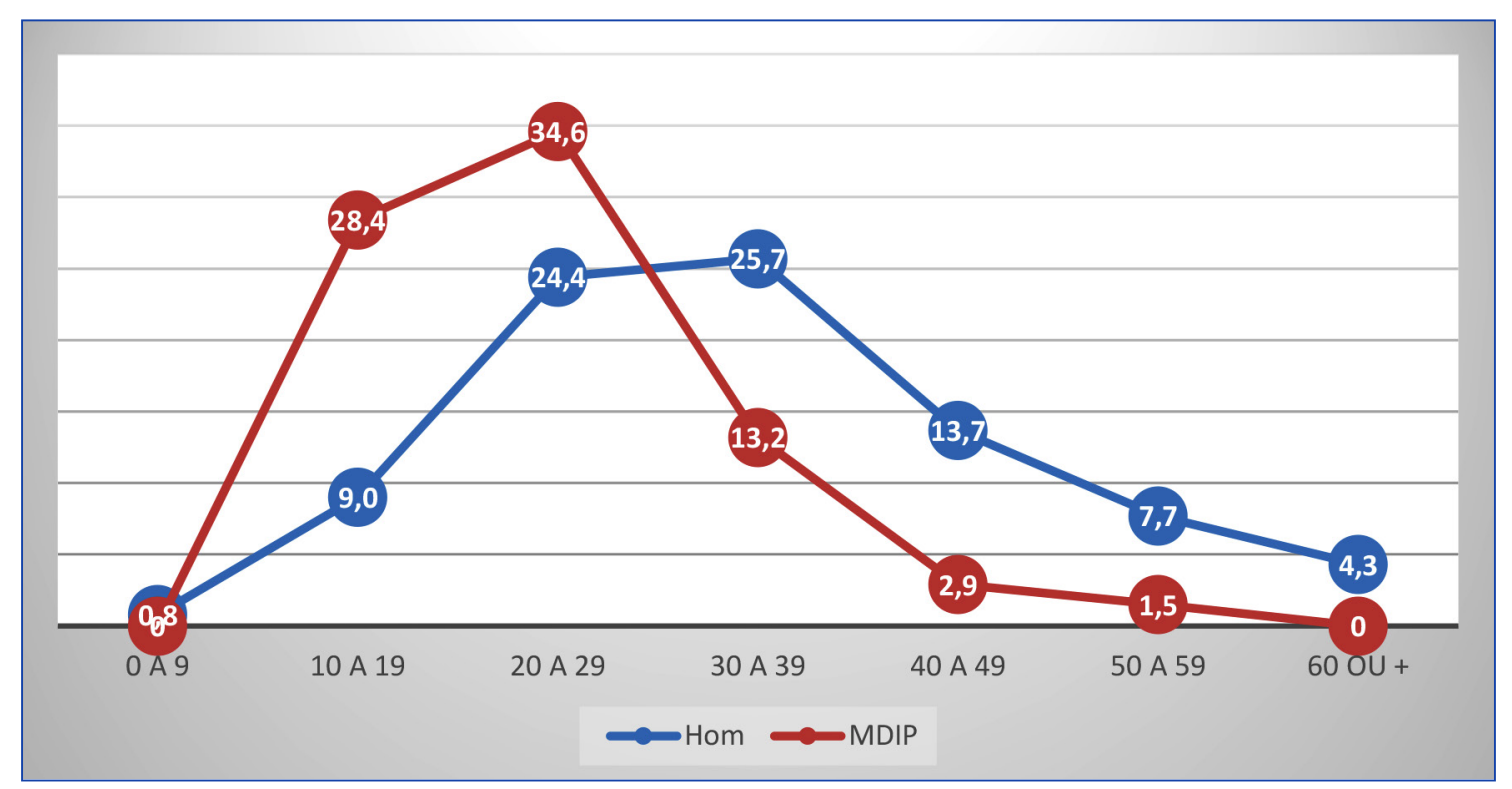

Fonte: Elaborado pelos autores a partir dos dados da CAP/SSP.

\section{CONCLUSÃO}

Parte significativa da literatura tem indicado que a explicação para os níveis de letalidade policial pode estar justamente no perfil das vítimas, o que seria fruto da seletividade dos agentes estatais ou do racismo institucional presente nas corporações (BRUNSON e MILLER, 2006; CANO, 2014; KLINGER, 1997; SCHLITTLER, 2016; SINHORETTO, BATITUCCI, MOTA et al., 2014). Adicionalmente, outros pesquisadores também indicam que o fato de as vítimas serem pessoas de baixa renda e viverem em territórios periféricos pode ser um fator que não gera comoção da opinião pública, encorajando policiais a adotarem um padrão de uso da força mais violento nesses territórios.

Seja como for, os dados indicam uma sobrerrepresentação de pretos e pardos e de jovens entre as vítimas da letalidade policial, mesmo quando comparados com as vítimas de homicídio, tendência que cresceu apesar da redução dos homicídios no Estado. Se do ponto de vista normativo, o uso da força policial deve obedecer aos critérios de proporcionalidade, moderação e legalidade, sendo utilizada somente quando há o risco de morte para o policial ou para terceiro, não parece lógico que a violência empregada pela polícia cresça com a redução dos homicídios no território.

Um elemento que tem sido pouco discutido pela literatura especializada e que parece ser crucial na compreensão dos números apresentados diz respeito à discricionariedade do policial que está na ponta em relação à implementação do policiamento. É o burocrata do nível de rua que faz a política no dia a dia e seu controle é extremamente desafiador em qualquer política pública (SABATIER, 1986). No entanto, quando falamos de um agente estatal que pode decidir sobre a vida ou a morte de um cidadão, isso se torna ainda mais complexo. 
Cabe ao profissional que está no nível de rua decidir sobre o tipo e a intensidade da ação policial mais adequados à determinada situação, e, dado o seu caráter discricionário e coercitivo, o Governo e seus instrumentos devem estabelecer, delimitar e monitorar os limites de uso da força do mandato policial; afinal, a ação institucional manifesta-se no modo como seus membros agem (BAYLEY, 2006). Essa variável é crucial não apenas para compreendermos o padrão de uso da força empregado, mas principalmente para pensarmos respostas adequadas aos casos em que se verificam abusos e ilegalidades. Neste caso, 0 Ministério Público e as Ouvidorias de Polícia podem constituir importantes mecanismos de controle externo da atividade policial quando atuantes; no entanto, tendem a ser menos eficientes.

Em geral os mecanismos de controle interno das polícias são mais eficientes porque a regulação interna tem acesso a um volume maior de informações em comparação com os atores externos, permitindo abordagem mais completa e mais rápida. Os mecanismos de controle interno às corporações policiais também podem abranger um número maior de casos, não se restringindo aos de maior repercussão, e podem utilizar meios formais e informais para garantir sua execução, sendo mais provável a força policial obedecer a uma regulação do comando do que se comportar de determinada maneira pela ameaça de uma regulação externa (BAYLEY, 2006; BUENO, 2014).

Outro fator a ser considerado é que normalmente os mecanismos de controle externo são vistos com desconfiança pelas polícias, que o entendem como um mecanismo punitivo e não como um regulador de condutas. Como desdobramento, a disseminação de agências de controle externo acaba por gerar ameaça à autonomia organizacional e as polícias a esconderem informações e erros (BAYLEY, 2006). Na tentativa de manter o vínculo com os profissionais de baixa patente, os oficiais tendem a encobrir erros de seus subordinados, o que enfraquece mais ainda a capacidade de autorregulação. Por conseguinte, a instituição controla menos e, portanto, as infrações ocorrem com maior frequência; a população perde a confiança na polícia; e os mecanismos de controle externo se fazem ainda mais necessários. Isso porque, embora nem sempre sejam os mais eficientes, os controles externos por vezes são os únicos disponíveis (BUENO, 2014).

Os dados apresentados e sua evolução histórica demonstram que as polícias paulistas têm feito uso excessivo da força letal segundo uma lógica que indica um padrão de seletividade que vitima desproporcionalmente pretos e pardos, adolescentes e jovens. Essa tendência se acirra entre 2013 e 2016 com o crescimento da letalidade policial, mesmo diante da redução do principal indicador da violência de um território, que é o homicídio. Compreender estas ações e diferenciar aquelas em que houve o uso legítimo da força dos casos abusivos e violentos dependem necessariamente de uma análise em profundidade de cada caso, o que só será efetivo com o envolvimento ativo das corregedorias, principal mecanismo de controle interno das corporações.

O desafio é garantir corregedorias atuantes, mas que prestem contas à população de sua atuação, gerando relatórios públicos com resultados dos casos analisados, encaminhamentos dados aos casos, e fortalecendo a transparência das instituições policiais. Para tanto, um caminho seria fortalecer a agenda de accountability, em especial aquela dedicada a transformar uma enorme quantidade de dados produzidos pelas instituições de justiça criminal e segurança pública em indicadores de monitoramento e avaliação mais robustos (LIMA, 2018), que consigam jogar luz às dinâmicas e características das mortes decorrentes de intervenção policial no país. 


\section{REFERÊNCIAS}

BAYLEY, D. H. Police for the future. New York: Oxford Univeristy Press, 1994.

BAYLEY, D. H. Padrões de Policiamento. São Paulo: Edusp, 2006.

BIDERMAN, C., DE MELLO, J.; SCHNEIDER, A. Dry Law and Homicides: Evidence from the São Paulo Metropolitan Area. Departamento de Economia, PUC-Rio: Texto para Discussão n. 518, 2006.

BITTNER, E. Aspectos do trabalho policial. São Paulo: Edusp, 2003.

BRASIL. Portaria Interministerial SDH/MJ no 4.226, de 31 de dezembro de 2010, que estabelece diretrizes sobre o uso da força pelos agentes de segurança pública. Diário Oficial da União, 03 jan. 2011. n. 1, Seção 1, p. 27.

BRETAS, M. L.; PONCIONI, P. A cultura policial e o policial civil carioca. In: PANDOLFI, D. C. et al. (Org.). Cidadania, justiça e violência. Rio Janeiro: Editora FGV, 1999. p. 149-163.

BRUNSON, R. K.; MILLER, J. Young Black Men and Urban Policing in the United States. British Journal of Criminology, v. 46, p. 613-40, 2006.

BUENO, S. Bandido bom é bandido morto: a opção ideológicoinstitucional da política de segurança pública na manutenção de padrões de atuação violentos da polícia militar paulista. 2014. $145 \mathrm{f}$. Dissertação (Mestrado em Administração Pública e Governo) - Escola de Administração de Empresas de São Paulo, Fundação Getulio Vargas, São Paulo, 2014.

CANO, I. Letalidade da ação policial no Rio de Janeiro. Rio de Janeiro: ISER, 1997.

CANO, I. Viés racial no uso da força letal pela polícia no Brasil. MPMG Jurídico, v. 1, p. 17-25, 2014.

CHEVIGNY, P. Edge of the knife: police violence in the Americas. New York: New York Press, 1995.

COSTA, A. T. M. Entre a lei e a ordem: violência e reforma nas polícias do Rio de Janeiro e Nova York. São Paulo: Editora FGV, 2004.

DIAS, C. N. Da guerra à gestão: a trajetória do Primeiro Comando da Capital (PCC) nas prisões de São Paulo. Revista Percurso: Sociedade, Natureza e Cultura, Ano VIII, v. 2, n. 10, p. 79-96, 2009.

FELTRAN, Gabriel de Santis. Crime e castigo na cidade: os repertórios da justiça e a questão do homicídio nas periferias de São Paulo. Cad. CRH, Salvador, v. 23, n. 58, p. 59-73, abr. 2010. Disponível em: <http://dx.doi.org/10.1590/S0103-49792010000100005>. Acesso em: 28 jul. 2019.

FELTRAN, G. S. Governo que produz crime, crime que produz governo: o dispositivo de gestão do homicídio em São Paulo (1992-2011). Revista Brasileira de Segurança Pública, v. 6, n. 2, 2012.

FERNANDES, H. R. Política e Segurança: Força Pública do Estado de São Paulo - fundamentos histórico-sociais. São Paulo: Editora AlfaOmega, 1973.

FERREIRA, S. P.; LIMA, R. S.; BESSA, V. Criminalidade Violenta e Homicídios em São Paulo: fatores explicativos e movimentos recentes. In: SILVA FILHO, T. J.; DURANTE, M. O. (Eds.). Homicídios: políticas de prevenção e controle. Brasília, DF: Ministério da Justiça; Porto Alegre: UFRGS, 2009. p. 11-20. (Coleção Segurança com Cidadania.
Vol. 3). p. 11-20. Disponível em: <https://goo.gl/6amFBT>. Acesso em: 23 nov. 2017.

FYFE, J. Blind Justice: Police Shootings in Memphis. Journal of Criminal Law and Criminology, v. 73, n. 2, p. 707-22, 1982.

FRYER JUNIOR, R. G. An empirical analysis of racial differences in police use of force. Cambridge: National Bureau of Economic Research, 2016. (Working Paper, n. 22399) Disponível em: < https:// doi.org/10.3386/w22399>. Acesso em: 18 jul. 2019.

FÓRUM BRASILEIRO DE SEGURANÇA PÚBLICA. Anuário Brasileiro de Segurança Pública, ano 9, 2015.

GELLER, W.; TOCH, H. (Ed.). Police violence: understanding and controlling police abuse of force. New Haven: Yale University Press, 1996.

INTITUTO SOU DA PAZ. Regulações sobre o Uso da Força pelas Polícias Militares dos estados de São Paulo e Pernambuco. In: SECRETARIA NACIONAL DE SEGURANÇA PÚBLICA. Direitos humanos. Brasília: Ministério da Justiça; Secretaria Nacional de Segurança Pública, 2013. (Coleção Pensando a Segurança Pública, v. 2).

JUSTUS. M.; KAHN, T.; CERQUEIRA, D. O “Mistério de São Paulo" e o Papel do PCC na redução de homicídios nos anos 2000. Campinas: UNICAMP, 2016.

KAHN, T.; ZANETIC, A. O papel dos municípios na segurança pública. Relatório final: concursos nacionais em pesquisas aplicadas em justiça criminal e segurança pública. Brasília: Secretaria Nacional de Segurança Pública, 2005.

KANIA, R.; MACKEY, W. Police violence as a function of community characteristics, Criminology, v. 15, n. 1, p. 27-48, 1977

KAPPELER, V. E.; SLUDER, R. D; ALPERT, G. P. Forces of deviance: understanding the dark side of policing. Long Grove: Waveland Press Inc., 1994.

KLINGER, D. A. Negotiating Order in Patrol Work: An Ecological Theory of Police Response to Deviance. Criminology, v. 35, n. 2, p. 277-306, 1997.

LESTER, D. Officer attitudes toward police use of force. In: GELLER, W. A.; $\mathrm{TOCH}, \mathrm{H}$. (Ed.). Police violence - understanding and controlling police abuse of force. New Haven: Yale University Press, 1996. p.180-190.

LIMA, R. S. Criminalité violente et homicides à São Paulo. L'Ordinaire des Amériques, v. 216, p. 1-10, 2014. Disponível em: <https://journals. openedition.org/orda/1138>. Acesso em: 18 jul. 2019.

LIMA, R.S. Violence and Public Safety as a Democratic Simulacrum in Brazil. International Journal of Criminology and Sociology, v. 7, p. 159-172, 2018.

LIPSKY, M. Street Level Bureaucracy: Dilemmas of the Individual in Public Services. New York, NY: The Russel Sage Foundation, 2010.

LOCHE, A. A letalidade de ação policial: parâmetros para análise. TOMO - Revista do Núcleo de Pós-Graduação e Pesquisa em Ciências Sociais, São Cristóvão, n. 17, jul./dez., 2010.

MANSO, B. P. Crescimento e queda dos homicídios em SP entre os anos de 1960 e $\mathbf{2 0 1 0 ~ - ~ U m a ~ a n a ́ l i s e ~ d o s ~ m e c a n i s m o s ~ d a ~ e s c o l h a ~}$ homicida e das carreiras no crime. 2012. Tese (Doutorado em 
Ciência Política) - Faculdade de Filosofia, Letras e Ciências Humanas, Universidade de São Paulo, São Paulo, 2012.

MELLO, J. M. P.; SCHENEIDER, A. Mudança demográfica e a dinâmica dos homicídios no Estado de São Paulo. São Paulo Perspectiva, v. 21, n. 1, p. 19-30, 2007.

MENA, F. Um a cada 3 brasileiros tem medo de violência e da polícia, aponta pesquisa. Folha de São Paulo, São Paulo, 03 jul. 2017. Disponível em <https://www1.folha.uol.com.br/cotidiano/2017/07/18979051-a-cada-3-brasileiros-tem-medo-de-violencia-e-da-policia-apontapesquisa.shtml>. Acesso em: 18 jul. 2019.

MISSE, M. et al. Quanto a polícia mata: homicídios por "autos de resistência" no Rio de Janeiro (2001-2011). 1. ed. v. 1. Rio de Janeiro: Booklink, 2013. p. 193.

MONJARDET, D. O que faz a polícia: Sociologia da Força Pública. Tradução: Mary Amazonas Leite de Barros. São Paulo: Edusp, 2002.

MUNIZ, J.; PROENÇA JÚNIOR, D.; DINIZ, E. Uso de força e ostensividade na ação policial. Conjuntura Política: Boletim de Análise, n. 6, p. 22-26, abr. 1999.

NERY, M. B. Crime e violência no cenário paulistano: o movimento e as condicionantes dos homicídios dolosos sob um recorte espaçotemporal. 2016. $207 \mathrm{f}$. São Paulo, 2016. Tese (Doutorado em Sociologia) - Faculdade de Filosofia, Letras e Ciências Humanas, Universidade de São Paulo, São Paulo, 2016.
PERES, M. F. T. et al. Queda dos homicídios em São Paulo, Brasil: uma análise descritiva. Revista Panamericana de Salud Pública, v. 29, p. 17-26, 2011.

SABATIER, P. A. What can we learn from implementation research? In: KAUFMAN, F. X.; MAJONE, G.; OSTROM, V. (Orgs.). Guidance, control and evaluation in the public sector: the Bielefeld interdisciplinary project. Berlin: De Gruyter, 1986. p. 313-325.

SINHORETTO, J. et al. A filtragem racial na seleção policial de suspeitos: segurança pública e relações raciais. In: SECRETARIA NACIONAL DE SEGURANÇA PÚBLICA. Segurança pública e direitos humanos: temas transversais. Brasília: Ministério da Justiça; Secretaria Nacional de Segurança Pública, 2014. (Coleção Pensando a Segurança Pública, v. 5).

SCHLITTLER, M. C. "Matar muito, prender mal”: A produção da desigualdade racial como efeito do policiamento ostensivo militarizado em SP. 2016. Tese (Doutorado em Sociologia) - Programa de PósGraduação em Sociologia, Universidade Federal de São Carlos, São Paulo, 2016.

SKOLNICK, J.; FYFE, J. Above the law: police and the excessive use of force. New York: Free Press, 1993.

WILLIS, G. A. N. The killing consensus: homicide detectives, police that kill and organized crime in São Paulo, Brazil. 2013. Thesis (Ph. D. in Urban and Regional Studies) -Massachusetts Institute of Technology, Dept. of Urban Studies and Planning, 2013.

Samira Bueno

ORCID: https://orcid.org/0000-0002-5784-148X

Doutora em Administração Pública e Governo pela Escola de Administração de Empresas da Fundação Getulio Vargas (FGV EAESP); Diretora-Executiva do Fórum Brasileiro de Segurança Pública, São Paulo - SP, Brasil. E-mail sbueno@forumseguranca.org.br

Renato Sérgio de Lima

ORCID: https://orcid.org/0000-0002-0935-699x

Doutor em Sociologia pela Universidade de São Paulo (USP); Diretor-Presidente do Fórum Brasileiro de Segurança Pública; Professor do Departamento de Gestão Pública pela Escola de Administração de Empresas da Fundação Getulio Vargas (FGV EAESP), São Paulo - SP, Brasil. E-mail: Renato.lima@fgv.br

Marco Antônio Carvalho Teixeira

ORCID: https://orcid.org/0000-0003-3298-8183

Doutor em Ciência Política pela Pontifícia Universidade Católica de São Paulo (PUC-SP); Professor do Departamento de Gestão Pública pela Escola de Administração de Empresas da Fundação Getulio Vargas (FGV EAESP), São Paulo - SP, Brasil. E-mail: marco.teixeira@fgv.br 